Article

\title{
Crystal Structure of Phosphoserine BlaC from Mycobacterium tuberculosis Inactivated by Bis(Benzoyl) Phosphate
}

\author{
Timothy W. Moural ${ }^{1,2, \dagger}$, Dawanna Shar-Day White ${ }^{1, \dagger}$, Cindy J. Choy ${ }^{1}$, Chulhee Kang ${ }^{1, * \mathbb{D}}$ and \\ Clifford E. Berkman ${ }^{1, *}$ \\ 1 Department of Chemistry, Washington State University, Pullman, WA 99164, USA \\ 2 Department of Entomology, Pennsylvania State University, University Park, PA 16802, USA \\ * Correspondence: chkang@wsu.edu (C.K.); cberkman@wsu.edu (C.E.B.); Tel.: +1-509-335-1409 (C.K.); \\ +1-509-335-7613 (C.E.B.) \\ + These authors contributed equally to this work.
}

Received: 10 June 2019; Accepted: 29 June 2019; Published: 2 July 2019 updates

\begin{abstract}
Mycobacterium tuberculosis, the pathogen responsible for tuberculosis (TB), is the leading cause of death from infectious disease worldwide. The class A serine $\beta$-lactamase BlaC confers Mycobacterium tuberculosis resistance to conventional $\beta$-lactam antibiotics. As the primary mechanism of bacterial resistance to $\beta$-lactam antibiotics, the expression of a $\beta$-lactamase by Mycobacterium tuberculosis results in hydrolysis of the $\beta$-lactam ring and deactivation of these antibiotics. In this study, we conducted protein $\mathrm{X}$-ray crystallographic analysis of the inactivation of $\mathrm{BlaC}$, upon exposure to the inhibitor bis(benzoyl) phosphate. Crystal structure data confirms that serine $\beta$-lactamase is phosphorylated at the catalytic serine residue (Ser-70) by this phosphate-based inactivator. This new crystallographic evidence suggests a mechanism for phosphorylation of BlaC inhibition by bis(benzoyl) phosphate over acylation. Additionally, we confirmed that bis(benzoyl) phosphate inactivated $\mathrm{BlaC}$ in a time-dependent manner.
\end{abstract}

Keywords: Mycobacterium tuberculosis; $\beta$-lactam antibiotic resistance; $\beta$-lactamase; phosphorylation; crystal structure

\section{Introduction}

According to the 2017 World Health Organization's (WHO) report, Mycobacterium tuberculosis, the pathogen responsible for tuberculosis (TB), is the leading cause of death from infectious disease worldwide [1]. In 2016 alone, there were more than 1.6 million deaths linked to TB infection. High incidences of new infections are reported annually, with 6.1 million new cases in 2015 and 6.3 million reported in 2016. In addition, there are growing threats of emerging multidrug-resistant (MDR-TB) and extensively drug resistant (XDR-TB) strains of Mycobacterium tuberculosis that are resistant to the current first-line, second-line, and third-line drugs used to treat TB [1,2]. The WHO estimates $4.1 \%$ of new TB infections and 19\% of those previously treated were caused by MDR-TB strains in 2016 [1].

With the emergence of MDR-TB and XDR-TB, novel research efforts are being focused on identifying new drug targets, such as enzymes of the nucleotide biosynthesis pathways and the TCA cycle [3]. Multiple novel antitubercular drugs are currently in the discovery phase and under clinical development [4]. One possible course of action to treat TB is to include $\beta$-lactam antibiotics to the list of agents used to treat TB infections [2,5]. Despite the successful use of $\beta$-lactam antibiotics to treat gram-negative and gram-positive bacterial infections over the last century, $\beta$-lactam antibiotics 
have not been commonly used to treat $\mathrm{TB}$ due to the expression of $\mathrm{BlaC}$, a $\beta$-lactamase capable of hydrolyzing their $\beta$-lactam ring $[2,6]$.

$\beta$-lactamases are categorized into four classes based on molecular characteristics, including sequence and structural similarities [6]. These four classes are A, B, C, and D, which can be classified into two main mechanistic groups. Class B $\beta$-lactamases are zinc metalloenzymes, while class A, C, and $\mathrm{D} \beta$-lactamases are serine $\beta$-lactamases [6,7]. $\mathrm{BlaC}$ is a class $\mathrm{A} \beta$-lactamase and due to its broad substrate specificity towards $\beta$-lactams, $\beta$-lactam antibiotics alone are not an efficacious treatment course for TB infections [8]. However, $M t b$ has demonstrated increased susceptibility to $\beta$-lactam antibiotics upon the inactivation of $\mathrm{BlaC}$, thus making $\mathrm{BlaC}$ an important target for therapeutic agents $[9,10]$.

With the emergence of pathogenic bacteria strains exhibiting broad-spectrum antibiotic resistance, it has been suggested that using a $\beta$-lactamase inhibitor in conjunction with a $\beta$-lactam antibiotic, could increase the likelihood of positive treatment outcomes $[8,11]$. To this point, $\beta$-lactam antibiotics have been used in conjunction with $\beta$-lactamase inhibitors as part of a multi-drug treatment regime for TB infections [2,11]. A number of studies have been undertaken to understand the evolution, enzyme structures, and catalytic mechanisms of various $\beta$-lactamases including BlaC $[2,7,8,12,13]$. Li and Pratt showed that acyl phosphonate scaffolds could be used to inhibit serine $\beta$-lactamases $[14,15]$. Herein, we provide crystal structure evidence to demonstrate that the serine $\beta$-lactamase BlaC can be phosphorylated at its nucleophilic serine by the novel $\beta$-lactamase inhibitors based on a bis(benzoyl) phosphate scaffold. These bis(benzoyl) phosphates are hypothesized to behave like traditional organophosphorylating agents that target serine hydrolases similar to acetylcholinesterase.

\section{Results}

\subsection{Crystal Structures of Phosphoserine BlaC and Inactivation by Bis(Benzoyl) Phosphate}

As noted above, Pratt and coworkers demonstrated that acyl phosphonantes and phosphates were inhibitors of $\beta$-lactamases. We postulated that this may be due to a time-dependent process involving either acylation or phosphorylation of the active-site Ser-70 reside. To explore the interaction of bis(benzoyl) phosphate with BlaC in more depth, we first confirmed that bis(benzoyl) phosphate inactivated $\mathrm{BlaC}$ in a time-dependent manner (Figures 1 and 2). In order to definitively determine this mechanism of inactivation, we sought to compare the crystal structure of BlaC inactivated with the bis(benzoyl) phosphate and the apo form of the enzyme, free of inhibitor.

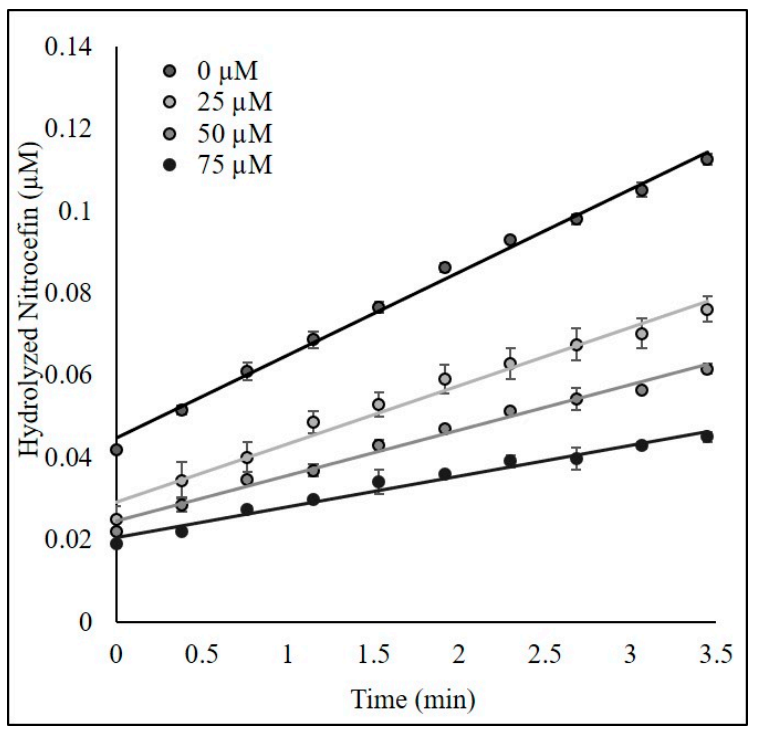

Figure 1. Dose-dependent curve for bis(benzoyl) phosphate after pre-incubation with BlaC. 
The crystal structures for both non-phosphoserine BlaC and phosphoserine BlaC were solved using molecular replacement using PDB 2GDN as the search model [6]. The non-phosphoserine BlaC is represented in Figure 2 and Table 1. The phosphoserine structure resolved to $1.52 \AA$ (Table 1). The $\mathrm{R}$-work and R-free for the phosphoserine structure were 0.16 and 0.17 , respectively.

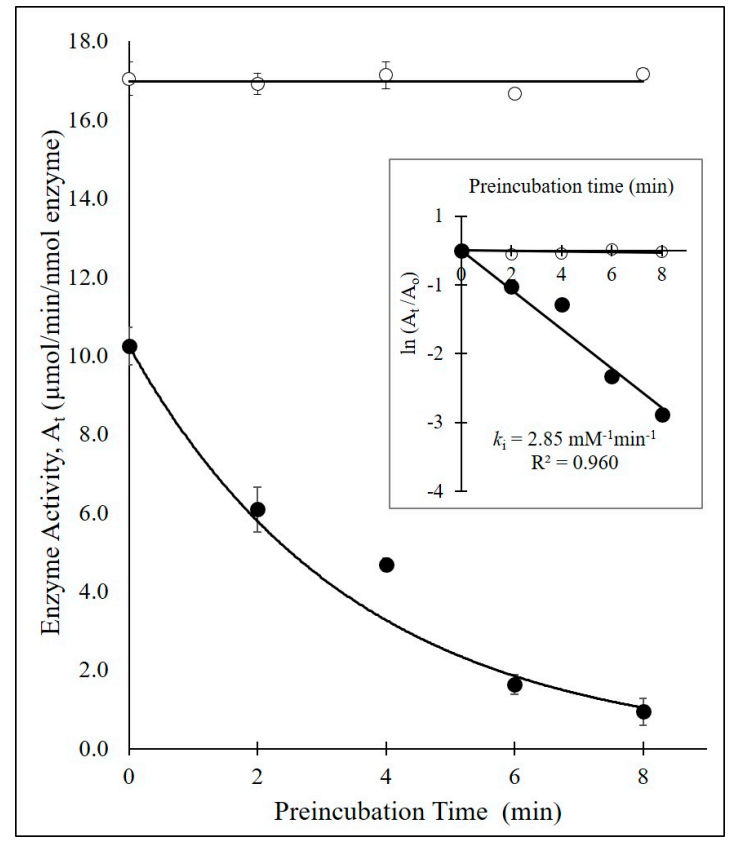

Figure 2. Time-dependent inhibition of BlaC by bis(benzoyl) phosphate (black circles) and BlaC without inhibitor (open circles). Inset figure: replot of the time-dependent residual enzyme activity to determine the bimolecular rate constant $k_{\mathrm{i}}\left(2.85 \mathrm{mM}^{-1} \cdot \mathrm{min}^{-1}\right)$ for the inhibition of BlaC by bis(benzoyl) phosphate.

Table 1. Crystal data table, parentheses refer to highest resolution shell.

\begin{tabular}{|c|c|}
\hline Data collection & BlaC - phosphoserine \\
\hline PDB ID & $6 \mathrm{~N} 14$ \\
\hline Space group & $\mathrm{P} 2_{1} 2_{1} 2_{1}$ \\
\hline \multicolumn{2}{|l|}{ Cell dimensions } \\
\hline$(a, b, c)(\AA)$ & $49.84,68.04,75.45$ \\
\hline Molecules per asymetric unit & 1 \\
\hline Resolution $(\AA)$ & $28.10-1.52$ \\
\hline Wavelength $(\AA)$ & 1.00 \\
\hline$R_{\text {sym }}$ & $0.099(0.816)$ \\
\hline $\mathrm{I} / \sigma$ & $17.6(1.92)$ \\
\hline $\mathrm{CC}_{1 / 2}$ & $0.992(0.623)$ \\
\hline Completeness & $99.75(97.88)$ \\
\hline Redundancy & $6.8(4.7)$ \\
\hline \multicolumn{2}{|l|}{ Refinement } \\
\hline Resolution $(\AA)$ & $28.10-1.52$ \\
\hline Unique reflections & $39,978(3,879)$ \\
\hline $\mathrm{R}_{\text {work }} / \mathrm{R}_{\text {free }}$ & $0.155 / 0.169$ \\
\hline \multicolumn{2}{|l|}{ RMSD } \\
\hline RMSD bonds ( & 0.003 \\
\hline RMSD angles $(\AA)$ & 0.745 \\
\hline \multicolumn{2}{|l|}{ Ramachandrans (\%) } \\
\hline Favored & 98 \\
\hline Outliers & 0 \\
\hline Number of atoms & 2,322 \\
\hline Protein and ligand & 1,999 \\
\hline Water & 323 \\
\hline
\end{tabular}


The phosphoserine crystal was in the $\mathrm{P} 2{ }_{1} 2_{1} 2_{1}$ space group. In the case of the phosphoserine crystal, Ser-70 showed clear density for a phosphoserine having been phosphorylated by the inhibitor bis(benzoyl) phosphate (Figure 3A). Additionally, the phosphoserine BlaC structure contained phosphate molecules near the active site adjacent to the nucleophilic Ser-70 (Figure 3B). In the phosphoserine structure, the distance between the oxygen atom of the phosphorylated Ser-70 and the phosphorus atom of the closest phosphate molecule was $4.5 \AA$ (phosphate pictured above Ser-70 in Figure $3 \mathrm{~B}$ ). The second phosphate molecule pictured at the bottom of Figure 4 was located $9.1 \AA$ from the oxygen atom of the phosphorylated Ser-70. The presence of phosphate molecules adjacent to the active site has previously been reported for BlaC structures as crystallization artifacts, including one in which BlaC was not crystallized with phosphate as the principal component of the crystallization condition and was instead thought to have been a byproduct of purification $[16,17]$. In addition, even though the previously published BlaC structures contain phosphate molecules near the active site, they do not have a phosphorylated Ser-70. Hereto, the phosphoserine-BlaC (Figure 3) newly demonstrates phosphorylation of the Ser-70 of BlaC.

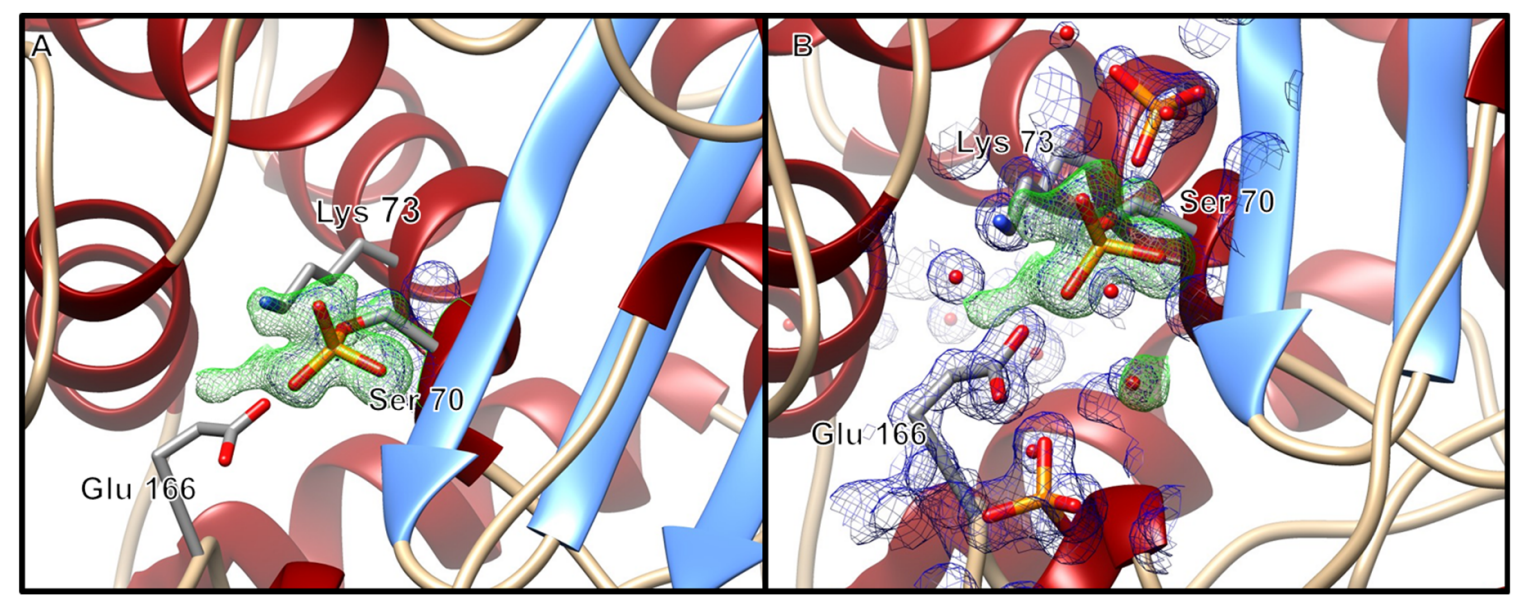

Figure 3. (A) Ribbon diagram of the phosphoserine BlaC structure, zoomed in to display electron density about the nucleophilic Ser-70. (B) Ribbon diagram of the phosphoserine BlaC structure, with additional phosphate molecules and water molecules with electron density about the active site. The ribbon diagrams have electron density displayed within $3 \AA$ of Ser-70, phosphate molecules and water molecules as a blue mesh at a $1.5 \sigma$ contour level for the $2 \mathrm{mFo}-\mathrm{DFc}$ maps, and the mFo-DFc maps contoured at $\pm 3 \sigma$ (green mesh/red mesh). The displayed mFo-Fc map was generated prior to modeling the phosphorylated Ser-70. The figure was generated with UCSF Chimera v1.12.

\subsection{Overall Structure and Active Site}

As previously reported for BlaC and other class A serine $\beta$-lactamases such as TEM-1, SHV-1, and the CTXMs, the global fold consists of two domains, the $\alpha$-domain and the $\alpha / \beta$-domain (Figure 4) [8,18-20]. Located in the $\alpha$-domain, adjacent to the $\alpha / \beta$-domain, are the catalytic residues Ser-70, Lys-73 and Glu-166 (numbered according to Ambler notation [21]). Structural sequence alignment showed that the primary sequence and the global fold of the $\alpha$-domain and the $\alpha / \beta$-domain were highly conserved throughout class A serine $\beta$-lactamases (Figure 5). In the case of BlaC, the $\alpha$-domain was made up of helices 2 through 11 , and the $\alpha / \beta$-domain consisted of helices $1,12,13$, and 14. In addition, the active site exhibits a high degree of conservation for the catalytic residues Ser-70, Lys-73 and Glu-166. 


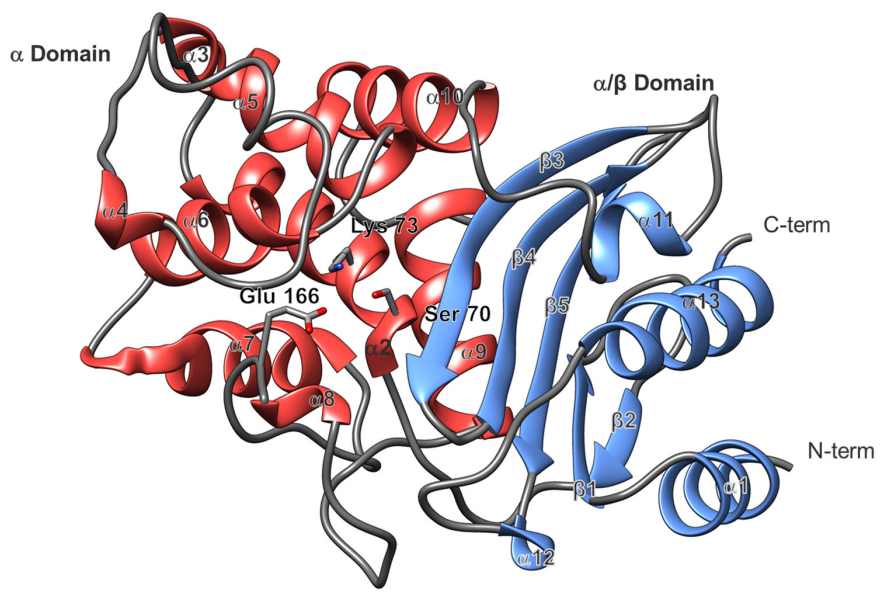

Figure 4. Global BlaC structure. The $\alpha$-domain is shown in red and the $\alpha / \beta$ domain is shown in cornflower blue. The active site is positioned toward the center showing the catalytic Ser-70, Lys-73, and Glu-166. Secondary structure numbering corresponds to Figure 5. The figure was generated with UCSF Chimera v1.12.

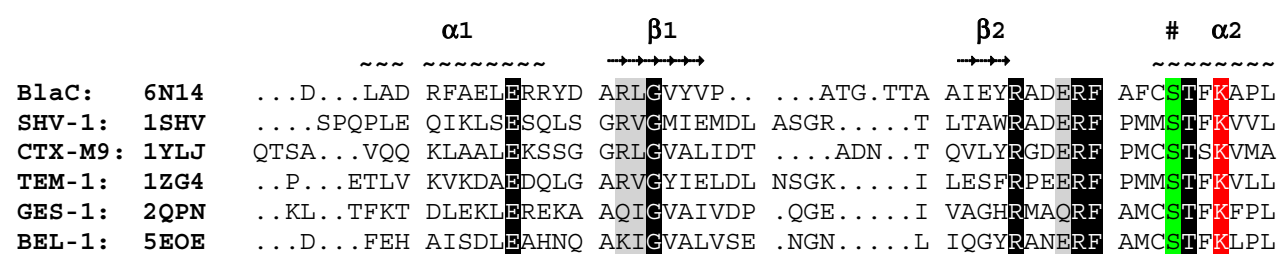

BEL-1: 5EOE

$\begin{array}{ll} & \\ \text { BlaC: } & 6 \mathrm{~N} 14 \\ \text { SHV-1: } & 1 \mathrm{SHV} \\ \text { CTX-M9: } & 1 \mathrm{YLJ} \\ \text { TEM-1: } & 1 \mathrm{ZG4} \\ \text { GES-1: } & 2 \mathrm{QPN} \\ \text { BEL-1: } & 5 \mathrm{EOE}\end{array}$

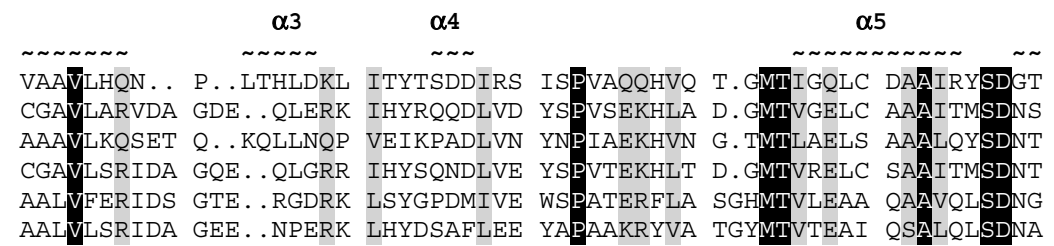

$\alpha 6$

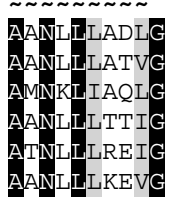

$\alpha 7$

$\alpha 8$

$\alpha 9$

$\begin{array}{ll}\text { BlaC: } & 6 \mathrm{~N} 14 \\ \text { SHV-1: } & 1 \mathrm{SHV} \\ \text { CTX-M9: } & 1 \mathrm{YLJ} \\ \text { TEM-1: } & 1 \mathrm{ZG4} \\ \text { GES-1: } & 2 \mathrm{QPN} \\ \text { BEL-1: } & 5 \mathrm{EOE}\end{array}$

BEL-1: 5EOE

$\begin{array}{ll} & \\ \text { BlaC: } & 6 \mathrm{~N} 14 \\ \text { SHV-1: } & 1 \mathrm{SHV} \\ \text { CTX-M9: } & 1 \mathrm{YLJ} \\ \text { TEM-1: } & 1 \mathrm{ZG4} \\ \text { GES-1: } & 2 \mathrm{QPN} \\ \text { BEL-1: } & 5 \mathrm{EOE}\end{array}$

Blac: $6 \mathrm{~N} 14$

SHV-1: 1SHV

CTX-M- $9: 1$ YLJ

TEM-1: 1ZG4

GES-1: 2QPN

BEL-1: 5EOE
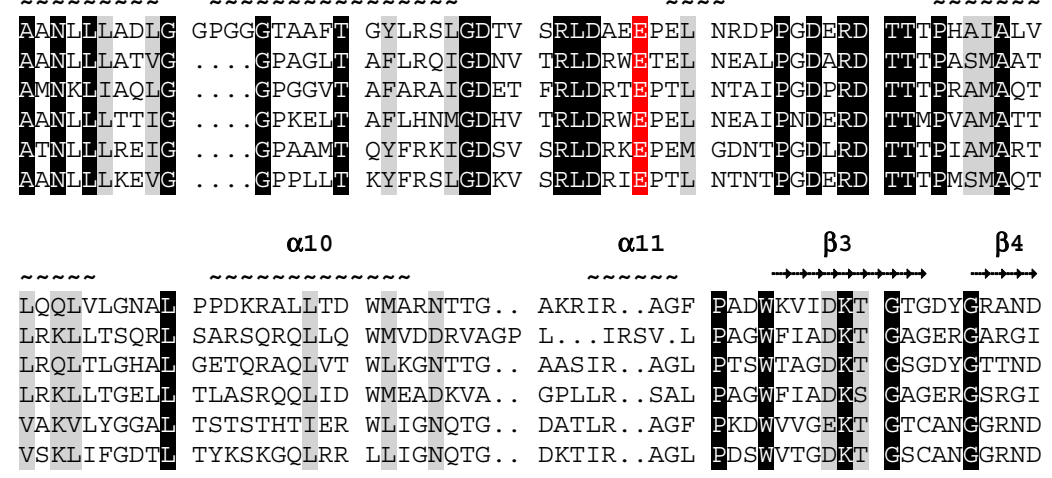

$\alpha 10$

$\alpha 13$

IAVVWSPT.G .VPYVVAVMS DRAGGGYDAE P. REALLAE AATCVAGVLA $\ldots \ldots$ VALLGPN.NK A.ERIVVIYL RDT.P...AS MAERNQQIAG IGAALIEHW. .Q.R. . IAVIWPQG.R . APLVLVTYF TQP. .QQNAE S..RRDVLAS AARIIAEGL. ..... IAALGPD.GK P.SRIVVIYT TGS.Q...AT MDERNRQIAE IGASLIKHW. ..... IGFFKAQ..E .RDYAVAVYT TAP.K...LS AVERDELVAS VGQVITQLIL ST..DK VAFFITTA.G .KKYVLSVYT NAP.E...LQ GEERALLIAS VAKLARQYV. .VH...

Figure 5. Structural sequence alignment of $\mathrm{BlaC}$ with five other class A serine $\beta$-lactamases. The protein name and representative PDB ID numbers are listed. Above the sequence, the position of the helices $(\sim)$ and beta strands $(\rightarrow)$ are indicated and numbered. The nucleophilic Ser-70 is highlighted in green and the catalytic Lys-73 and Glu-166 are highlighted in red. 


\section{Discussion}

BlaC, a hydrolase (EC 3.5.2.6), cleaves lactam carbon-nitrogen amide bonds rapidly, effectively deactivating $\beta$-lactam antibiotics [22,23]. This $\beta$-lactam hydrolysis proceeds through an acylation-deacylation reaction. During acylation, Lys-73 acts as a general-base catalyzing the nucleophilic Ser-70 attack of the lactam carbonyl carbon and formation of a tetrahedral intermediate [22-24]. The collapse of the tetrahedral intermediate proceeds to the oxyanion-hole stabilized acyl-enzyme adduct. Deacylation proceeds as Glu-166 acts as a general-base and catalyzes a hydrolytic water attack on the carbonyl carbon of the adduct, resulting in the release of the inactive hydrolyzed $\beta$-lactam and return of BlaC to its resting state. Due to the efficiency of BlaC, as the main $\beta$-lactamase of tuberculosis (TB), to hydrolyze $\beta$-lactam antibiotics, the $\beta$-lactam class of antibiotics proved ineffective in treating (TB) $[2,5,6]$.

It had been proposed by Pratt and colleagues that phosphate-based compounds could serve as effective inhibitors of $\beta$-lactamases [25-28]. They first demonstrated that a phosphonate monoester inhibited the activity of the class C $\beta$-lactamase P99 towards benzylpenicillin [25]. However, upon incubation of the same phosphonate monoester with class A and class D $\beta$-lactamases, little inhibition effect was observed. Later work by Rahil and Pratt showed that modifications to the leaving group could expand the inhibitory potency of phosphonates to include class A $\beta$-lactamases [26]. They proposed that the mechanism of action for these phosphonates on $\beta$-lactamase inhibition directly resulted from nucleophilic Ser-70 phosphorylation. A subsequent crystal structure 1BLH showed a phosphonate inhibitor covalently bound to the Ser-70 of a $\beta$-lactamase from Staphylococcus aureus as an acyl-enzyme intermediate complex [29]. Building on the promising data by Pratt et al., we proposed using the bis(benzoyl) phosphate to inhibit the activity of the class A $\beta$-lactamase BlaC. Upon pre-incubation of the bis(benzoyl) phosphate with BlaC, there was a noted reduction in enzymatic activity as compared to the uninhibited $\mathrm{BlaC}$ and time zero preincubation time (Figure 3).

We surmised that the inactivation of BlaC with bis(benzoyl) phosphate could follow either an acylation or phosphorylation type of mechanism, the latter being consistent with the inactivation of other serine hydrolases with organophosphates [30-32]. Even though these compounds contain an acylation site that could lead to an acylated inhibition mechanism, in proposing the phosphorylation mechanism over the acylation mechanism by the bis(benzoyl) phosphate, two equivalents of benzoate would have been released (Figure 6). Consistent with the proposed phosphorylation mechanism, we did not observe an intact inhibitor, nor released benzoates in the active site after the phosphorylation step occurred. Indeed, we hypothesized that a phosphorylation mechanism could be responsible for the mode of inactivation of BlaC with bis(benzoyl) phosphate based on the crystal structure of BlaC, in which Ser-70 is shown to be phosphorylated (Figure 3). Now it should be noted that other groups have demonstrated that the presence of inorganic phosphate in the active site has been shown to reestablish BlaC activity after inactivation by clavulanic acid [17].

It is known that esterase enzymes can be phosphorylated at their nucleophilic serine residues upon exposure to organophosphates through a mechanism of inactivation followed by aging [31-34]. However, there was no precedence in the literature for the phosphorylation of the active site serine of BlaC, thus it was unknown whether the Ser-70 of BlaC could be irreversibly modified by a phosphorus ligand. We confirmed that when $\mathrm{BlaC}$ is incubated with a $\beta$-lactamase phosphorylating agent, bis(benzoyl) phosphate, nucleophilic serine phosphorylation occurs based on crystallographic data. In addition, even though the bis(benzoyl) phosphate can theoretically inactivate through an acylation mechanism, the scaffold proceeds through phosphorylation. We propose this occurs via an irreversible time-dependent mechanism based on preliminary inhibitory potency studies (Figures 2 and 3). In theory, the inhibition mechanism involves the Ser-70, Lys-73, Glu-166 and a catalytic water molecule (Figure 6). First, the sidechain amine of Lys-73 deprotonates the hydroxymethyl group of Ser-70. The deprotonated oxyanion of Ser-70 then attacks the phosphorus atom of the bis(benzoyl) phosphate inhibitor and a benzoate group leaves, forming a benzoyl phosphoserine intermediate. Lastly, hydrolysis by a water molecule, deprotonated by the carboxyl sidechain of Glu-166, results in the loss of the second benzoate group, resulting in the aged BlaC being phosphorylated at the 
nucleophilic Ser-70, not unlike the aged forms of cholinesterase and chymotrypsin inactivated by organophosphorus agents $[32,35,36]$. However, further studies will need to be conducted to further elucidate the specific amino acid interactions. Due to the novelty of the inactivation of BlaC by the bis(benzoyl) phosphate compound, there is still a vast amount to be investigated.

Presently, the bis(benzoyl) phosphate represents the only phosphorus-containing scaffold that we tested, which inactivated BlaC. Other phosphorus-containing compounds that were tested for inhibition properties included phosphonates and phosphothioesters. A plausible reason why the bis(benzoyl) phosphate scaffold worked over other organophosphate scaffolds might involve the electrophilic nature of the phosphorus center and the pKa of the leaving groups' conjugate acids (e.g., benzoic acids vs. alcohols and thiols) [30-32,37]. This new crystal-structure evidence suggests the inactivation mechanism of $\mathrm{BlaC}$ involves the unsubstituted bis(benzoyl) phosphate via nucleophilic Ser-70 phosphorylation, and is expected to aid in the design of future novel $\beta$-lactamase inactivators utilizing a phosphorylating scaffold. In the future, these phosphorylating agents can potentially be used concurrently with a $\beta$-lactam antibiotic for the treatment of $\beta$-lactam antibiotic-resistant bacterial infections.

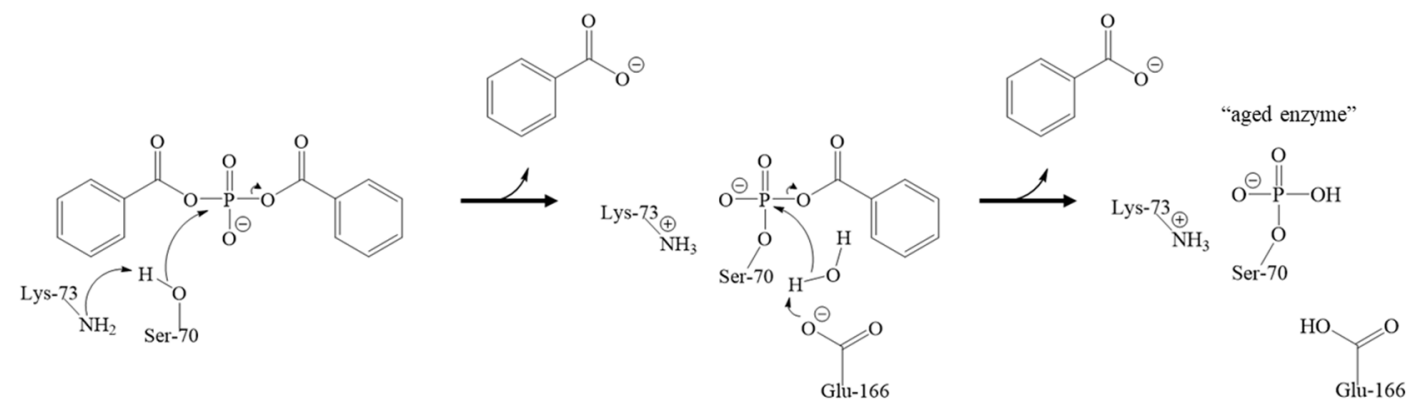

Figure 6. Proposed inactivation mechanism of BlaC. The nucleophilic Ser-70 is deprotonated by Lys-73, which then attacks the phosphorus atom of bis(benzoyl) phosphate, and benzoate leaves. Glu-166 then deprotonates a catalytic water molecule, which attacks the phosphorus to displace the second benzoate, leading to the phosphorylation of Ser-70 and resulting in an aged form of the enzyme.

\section{Materials and Methods}

\subsection{Expression and Purification}

Escherichia coli strain BL21 (DE3) transformed with a pET28 plasmid containing the Mycobacterium tuberculosis gene blaC kindly provided by Dr. Blanchard was used for expression of a truncated version of the $\beta$-lactamase protein. The gene was isolated from Mycobacterium tuberculosis strain ATCC 25618/H37Rv. The coding region for the first 40 amino acids was removed from the blaC gene to aid expression. To express $\beta$-lactamase, Luria-Bertani broth was inoculated with transformed $E$. coli cells and incubated at $37^{\circ} \mathrm{C}$ until a 0.5 to 0.6 optical density at $600 \mathrm{~nm}$ was reached. Cells were then cooled and incubated at $20^{\circ} \mathrm{C}$ in a shaker set at $200 \mathrm{rpm}$ for $20 \mathrm{~h}$. After incubation, cells were collected and centrifuged at 3,000 g for $15 \mathrm{~min}$. Pelleted cells were then collected and frozen at $-20^{\circ} \mathrm{C}$ until purification.

For purification, frozen cell pellets were suspended in lysis/wash buffer containing $20 \mathrm{mM}$ Tris, $300 \mathrm{mM} \mathrm{NaCl}$, and $20 \mathrm{mM}$ imidazole at $\mathrm{pH}$ 8.5. The resuspended cells were sonicated with a Branson Sonifier ${ }^{\mathrm{TM}} 450$ (Branseon Ultrasonics, Danbury, CT, U.S.A.) to release soluble protein and then centrifuged at 15,000 $\mathrm{g}$ for $30 \mathrm{~min}$. The supernatant was added to a Ni-NTA column (Bio-Rad, CA, U.S.A.). The Ni-NTA was then washed with 10 column volumes of the lysis/wash buffer. $\beta$-lactamase was eluted from the Ni-NTA column with a buffer containing $20 \mathrm{mM}$ Tris, $300 \mathrm{mM} \mathrm{NaCl}$, and $250 \mathrm{mM}$ imidazole at $\mathrm{pH}$ 8.5. Next, the eluted $\beta$-lactamase was buffer exchanged into buffer A ( $20 \mathrm{mM}$ Tris $\mathrm{pH}$ 8.5, 2 mM DTT, 5\% glycerol) for purification on a GE ÄKTA pure FPLC system (GE Healthcare, PA, U.S.A.) connected to a Resource ${ }^{\mathrm{TM}} \mathrm{Q}$ (GE Healthcare, PA, U.S.A.) column. $\beta$-lactamase BlaC was eluted 
from the Resource ${ }^{\mathrm{TM}} \mathrm{Q}$ column by running a gradient of buffer $\mathrm{A}$ to buffer $\mathrm{B}$ ( $20 \mathrm{mM}$ Tris $\mathrm{pH}$ 8.5, 2M $\mathrm{NaCl}, 5 \%$ glycerol). Purified $\beta$-lactamase fractions were collected for future use based on SDS-PAGE.

\subsection{Synthesis of the Bis(Benzoyl) Phosphate}

Pyridine $(2 \mathrm{~mL})$ was added to a $20 \mathrm{~mL}$ scintillation vial containing $20-25$ glass beads $(5 \mathrm{~mm})$ and $1 \mathrm{~g}$ (7.04 mmol) sodium phosphate (dibasic, anhydrous). The slurry was vortexed for $2-5 \mathrm{~min}$ before the addition of the acyl chloride derivative ( $15.49 \mathrm{mmol}, 2.2$ equivalences). After the addition, the reaction vial was continuously vortexed for $1 \mathrm{hr}$. Afterwards, a solution of $10 \% \mathrm{HCl}_{(\mathrm{aq})}$ : ethyl acetate $(1: 1, v / v)$ was added to the crude reaction mixture then transferred into a separatory funnel. The aqueous layer was extracted $3 \times$ with ethyl acetate and the organic layers were pooled together then washed $3 \times$ with saturated sodium chloride solution. The precipitant which formed during each brine wash was collected and placed on a vacuum to remove residual water. The crude solid was further purified by reverse-phase (RP) C18 column chromatography (Flash Biotage, Sweden) using a gradient mobile phase $50 \%-70 \%$ acetonitrile: water $(v / v)$. White solid in $>99 \%$ isolated yield. ${ }^{1} \mathrm{H}$ NMR (400 MHz, DMSO-d6) 8: $7.97(\mathrm{t}, \mathrm{J}=1.6 \mathrm{~Hz}, 2 \mathrm{H}), 7.67(\mathrm{~d}, \mathrm{~J}=7.4 \mathrm{~Hz}, 1 \mathrm{H}), 7.54(\mathrm{t}, \mathrm{J}=7.9 \mathrm{~Hz}, 2 \mathrm{H})$. ${ }^{13} \mathrm{C}$ NMR (101 MHz, DMSO-d6) $\delta$ 162.30, 162.21, 133.66, 130.38, 130.31, 129.78, 128.82. ${ }^{31} \mathrm{P}$ NMR (122 MHz, DMSO-d6) $\delta-6.00$ (triphenyl phosphine std, s), -17.33(s). HRMS (MALDI) m/z calculated for $\mathrm{C}_{14} \mathrm{H}_{11} \mathrm{O}_{6} \mathrm{P}[\mathrm{M}+\mathrm{Na}]$ 329.0191; found [M + Na] 329.0186 ( $\left.\pm 1.6 \mathrm{ppm}\right)$.

\subsection{Time-Dependent Inhibition of BlaC}

To determine the bimolecular rate constant for the time-dependent inhibition of BlaC by bis(benzoyl) phosphate, BlaC was incubated with bis(benzoyl) phosphate in the absence of the substrate (nitrocefin) for increasing periods of time (0-8 min). Progress curves for the hydrolysis of nitrocefin to provide the residual enzyme activity $A_{t}$ were acquired using A Fluostar Omega Microplate Reader running Omega software version 1.02 and Mars Data Analysis Software Program version 1.10 (BMG Labtech. For each pre-incubation time point, $75 \mu \mathrm{L}$ of $10 \mathrm{nM}$ BlaC was added to replicate wells with $100 \mu \mathrm{M}$ of bis(benzoyl) phosphate in $100 \mathrm{mM}$ PIPES Buffer $\mathrm{pH}=7.4$ at $37^{\circ} \mathrm{C}$. After pre-incubation for each specified time point, the residual enzymatic activity was determined by the addition of $75 \mu \mathrm{L}$ of $100 \mu \mathrm{M}$ nitrocefin. The rate of product formation was determined by measuring the absorbance at $482 \mathrm{~nm}\left(\varepsilon=17,400 \mathrm{M}^{-1} \cdot \mathrm{cm}^{-1}\right)$ over the course of $8.7 \mathrm{~min}$ to generate an enzyme activity $\mathrm{A}_{\mathrm{t}}$ for each time point of preincubation ( $\mu \mathrm{mol} / \mathrm{min} / \mathrm{nmol}$ enzyme).

\subsection{Protein Crystallization and Structure Determination}

$\beta$-lactamase crystals were grown using the hanging-drop vapor diffusion method at $4{ }^{\circ} \mathrm{C}$. A modified crystallization solution of 0.1 M HEPES pH 7.4, 2.25 M ammonium phosphate monobasic was used [8]. Non-phosphoserine crystals were grown by making drops containing 1 part purified $\beta$-lactamase at $15 \mathrm{mg} / \mathrm{mL}$ in $20 \mathrm{mM}$ Tris $\mathrm{pH} 8.5,150 \mathrm{mM} \mathrm{NaCl}$ with 1-part crystallization solution and equilibrating against the same reservoir. For the $\beta$-lactamase Ser-70 phosphorylated crystals, drops contained 1 part purified $\beta$-lactamase at $15 \mathrm{mg} / \mathrm{mL}(0.46 \mathrm{mM})$ and the inhibitor at $1 \mathrm{mM}$ bis(benzoyl) phosphate in $20 \mathrm{mM}$ Tris $\mathrm{pH} 8.5,150 \mathrm{mM} \mathrm{NaCl}$. After the inhibitor and $\beta$-lactamase were gently mixed, the mixed protein and inhibitor solution was directly mixed without preincubation with 1-part crystallization solution and equilibrated against the reservoir solution. Crystals typically formed within two weeks. Prior to data collection, crystals were flash frozen using liquid nitrogen and the cryoprotectant 0.1 M HEPES pH 7.4, 2.25 M ammonium phosphate monobasic, and 20\% glycerol. Crystal data were collected at Advanced Light Source (ALS) beamlines 5.0.1 and 8.2.1. Diffraction data processing was done with the HKL2000 software package [38]. Molecular replacement was done using PHENIX Phaser and a previously solved $\beta$-lactamase (BlaC) with the same sequence (PDB: 2GDN) [8,39]. PHENIX and Coot were used for refinement and modeling [39,40]. 


\subsection{Sequence Alignment}

Structural comparison and sequence alignment of serine $\beta$-lactamases were conducted using UCSF Chimera software and the TM-align server to calculate c-alpha RMSD and TM-score [41,42]. Sequence identity and similarity were calculated using the LALIGN tool with alignment set for global without gap open penalty, available on the SIB ExPASy Bioformatics Resources Portal website. Serine $\beta$-lactamases with deposited crystal structures were found using the Beta-Lactamase Data Base and the corresponding models were downloaded from the PDB $[43,44]$. The MatchMaker tool in Chimera was used to generate the structural sequence alignment and crystal structure superposition [41]. The sequence alignment figure was generated with BioEdit and manually annotated [45].

Author Contributions: T.W.M., D.S.-D.W., C.J.C., C.K., and C.E.B., conceived and designed the experiments. T.W.M. and D.S.-D.W. performed the experiments. D.S.-D.W. synthesized the inhibitor. T.W.M. and C.K. analyzed the data. T.W.M. drafted the manuscript. C.J.C., C.K., and C.E.B. supervised the progress of the project. C.E.B. contributed reagents and materials. C.K. provided analysis tools. All authors contributed to the revision of the manuscript and approved the final manuscript.

Funding: This research was supported in part by a grant from the National Institutes of Health (1R21AI115157).

Acknowledgments: The authors would like to thank J. S. Blanchard from the Albert Einstein College of Medicine for the BlaC protein plasmid.

Conflicts of Interest: The authors declare no conflict of interest. The funding sponsors had no role in the design of the study; in the collection, analyses, or interpretation of data; in the writing of the manuscript, and in the decision to publish the results.

\section{References}

1. Laura Anderson, A.B.; Dean, A.; Dias, H.M.; Falzon, D.; Floyd, K.; Baena, I.G.; Gebreselassie, N.; Gilpin, C.; Glaziou, P.; Hamada, Y.; et al. Global Tuberculosis Report; World Health Organization: Geneva, Switzerland, 2017; Available online: https://www.who.int/tb/en/ (accessed on 26 March 2018).

2. Hugonnet, J.-E.; Tremblay, L.W.; Boshoff, H.I.; Barry, C.E.; Blanchard, J.S. Meropenem-Clavulanate Is Effective Against Extensively Drug-Resistant Mycobacterium tuberculosis. Science 2009, 323, 1215-1218. [CrossRef] [PubMed]

3. Ferraris, D.M.; Miggiano, R.; Rossi, F.; Rizzi, M. Mycobacterium tuberculosis Molecular Determinants of Infection, Survival Strategies, and Vulnerable Targets. Pathogens 2018, 7, 17. [CrossRef] [PubMed]

4. J Libardo, M.D.; Boshoff, H.I.M.; Barry, C.E. The present state of the tuberculosis drug development pipeline. Curr. Opin. Pharmacol. 2018, 42, 81-94. [CrossRef] [PubMed]

5. Prigozhin, D.M.; Krieger, I.V.; Huizar, J.P.; Mavrici, D.; Waldo, G.S.; Hung, L.-W.; Sacchettini, J.C.; Terwilliger, T.C.; Alber, T. Subfamily-Specific Adaptations in the Structures of Two Penicillin-Binding Proteins from Mycobacterium tuberculosis. PloS ONE 2014, 9, e116249. [CrossRef] [PubMed]

6. Bush, K.; Jacoby, G.A. Updated functional classification of beta-lactamases. Antimicrob. Agents Chemother. 2010, 54, 969-976. [CrossRef] [PubMed]

7. Hall, B.G.; Barlow, M. Evolution of the serine $\beta$-lactamases: Past, present and future. Drug Resist. Updates 2004, 7, 111-123. [CrossRef] [PubMed]

8. Wang, F.; Cassidy, C.; Sacchettini, J.C. Crystal Structure and Activity Studies of the Mycobacterium tuberculosis $\beta$-Lactamase Reveal Its Critical Role in Resistance to $\beta$-Lactam Antibiotics. Antimicrob. Agents Chemother. 2006, 50, 2762-2771. [CrossRef]

9. Kurz, S.G.; Wolff, K.A.; Hazra, S.; Bethel, C.R.; Hujer, A.M.; Smith, K.M.; Xu, Y.; Tremblay, L.W.; Blanchard, J.S.; Nguyen, L.; et al. Can inhibitor-resistant substitutions in the Mycobacterium tuberculosis $\beta$-Lactamase BlaC lead to clavulanate resistance?: A biochemical rationale for the use of $\beta$-lactam- $\beta$-lactamase inhibitor combinations. Antimicrob. Agents Chemother. 2013, 57, 6085-6096. [CrossRef]

10. Xu, H.; Hazra, S.; Blanchard, J.S. NXL104 irreversibly inhibits the beta-lactamase from Mycobacterium tuberculosis. Biochemistry 2012, 51, 4551-4557. [CrossRef]

11. Chambers, H.F.; Kocagöz, T.; Sipit, T.; Turner, J.; Hopewell, P.C. Activity of Amoxicillin/Clavulanate in Patients with Tuberculosis. Clin. Infect. Dis. 1998, 26, 874-877. [CrossRef] 
12. Mitchell, J.M.; Clasman, J.R.; June, C.M.; Kaitany, K.-C.J.; LaFleur, J.R.; Taracila, M.A.; Klinger, N.V.; Bonomo, R.A.; Wymore, T.; Szarecka, A.; et al. The structural basis of activity against aztreonam and extended spectrum cephalosporins for two carbepenem-hydrolyzing class D b-lactamases from Acinetobacter baumannii. Biochemistry 2015, 54, 1976-1987. [CrossRef] [PubMed]

13. Pozzi, C.; De Luca, F.; Benvenuti, M.; Poirel, L.; Nordmann, P.; Rossolini, G.M.; Mangani, S.; Docquier, J.-D. Crystal Structure of the Pseudomonas aeruginosa BEL-1 Extended-Spectrum $\beta$-Lactamase and Its Complexes with Moxalactam and Imipenem. Antimicrob. Agents Chemother. 2016, 60, 7189-7199. [PubMed]

14. Maveyraud, L.; Pratt, R.F.; Samama, J.-P. Crystal Structure of an Acylation Transition-State Analog of the TEM-1 $\beta$-Lactamase. Mechanistic Implications for Class A $\beta$-Lactamases. Biochemistry 1998, 37, 2622-2628. [CrossRef] [PubMed]

15. Li, N.; Pratt, R.F. Inhibition of Serine $\beta$-Lactamases by Acyl Phosph(on)ates: A New Source of Inert Acyl [and Phosphyl] Enzymes. J. Am. Chem. Soc. 1998, 120, 4264-4268. [CrossRef]

16. Hazra, S.; Kurz, S.G.; Wolff, K.; Nguyen, L.; Bonomo, R.A.; Blanchard, J.S. Kinetic and Structural Characterization of the Interaction of 6-Methylidene Penem 2 with the beta-Lactamase from Mycobacterium tuberculosis. Biochemistry 2015, 54, 5657-5664. [CrossRef] [PubMed]

17. Elings, W.; Tassoni, R.; van der Schoot, S.A.; Luu, W.; Kynast, J.P.; Dai, L.; Blok, A.J.; Timmer, M.; Florea, B.I.; Pannu, N.S.; et al. Phosphate Promotes the Recovery of Mycobacterium tuberculosis beta-Lactamase from Clavulanic Acid Inhibition. Biochemistry 2017, 56, 6257-6267. [CrossRef] [PubMed]

18. Chen, Y.; Delmas, J.; Sirot, J.; Shoichet, B.; Bonnet, R. Atomic Resolution Structures of CTX-M $\beta$-Lactamases: Extended Spectrum Activities from Increased Mobility and Decreased Stability. J. Mol. Biol. 2005, 348, 349-362. [CrossRef]

19. Kuzin, A.P.; Nukaga, M.; Nukaga, Y.; Hujer, A.M.; Bonomo, R.A.; Knox, J.R. Structure of the SHV-1 $\beta$-Lactamase. Biochemistry 1999, 38, 5720-5727. [CrossRef]

20. Stec, B.; Holtz, K.M.; Wojciechowski, C.L.; Kantrowitz, E.R. Structure of the wild-type TEM-1 [beta]-lactamase at $1.55 \mathrm{~A}$ and the mutant enzyme Ser70Ala at 2.1 A suggest the mode of noncovalent catalysis for the mutant enzyme. Acta Crystallogr. Sect. D 2005, 61, 1072-1079. [CrossRef]

21. Ambler, R.P.; Coulson, A.F.; Frere, J.M.; Ghuysen, J.M.; Joris, B.; Forsman, M.; Levesque, R.C.; Tiraby, G.; Waley, S.G. A standard numbering scheme for the class A beta-lactamases. Biochem. J. 1991, 276, 269-270. [CrossRef]

22. Vandavasi, V.G.; Weiss, K.L.; Cooper, J.B.; Erskine, P.T.; Tomanicek, S.J.; Ostermann, A.; Schrader, T.E.; Ginell, S.L.; Coates, L. Exploring the Mechanism of beta-Lactam Ring Protonation in the Class A beta-lactamase Acylation Mechanism Using Neutron and X-ray Crystallography. J. Med. Chem. 2016, 59, 474-479. [CrossRef] [PubMed]

23. Tremblay, L.W.; Fan, F.; Blanchard, J.S. Biochemical and Structural Characterization of Mycobacterium tuberculosis $\beta$-Lactamase with the Carbapenems Ertapenem and Doripenem. Biochemistry 2010, 49, 3766-3773. [CrossRef] [PubMed]

24. Pan, X.; He, Y.; Lei, J.; Huang, X.; Zhao, Y. Crystallographic Snapshots of Class A beta-Lactamase Catalysis Reveal Structural Changes That Facilitate beta-Lactam Hydrolysis. J. Biol. Chem. 2017, 292, 4022-4033. [CrossRef] [PubMed]

25. Pratt, R.F. Inhibition of a class C beta-lactamase by a specific phosphonate monoester. Science 1989, 246, 917-919. [CrossRef] [PubMed]

26. Rahil, J.; Pratt, R.F. Phosphonate monoester inhibitors of class A beta-lactamases. Biochem. J. 1991, 275, 793-795. [CrossRef] [PubMed]

27. Morrison, M.J.; Li, N.; Pratt, R.F. Inverse acyl phosph(on)ates: Substrates or inhibitors of beta-lactam-recognizing enzymes? Bioorganic Chem. 2001, 29, 271-281. [CrossRef] [PubMed]

28. Majumdar, S.; Pratt, R.F. Inhibition of Class A and C $\beta$-Lactamases by Diaroyl Phosphates. Biochemistry 2009, 48, 8285-8292. [CrossRef]

29. Chen, C.C.; Rahil, J.; Pratt, R.F.; Herzberg, O. Structure of a phosphonate-inhibited beta-lactamase. An analog of the tetrahedral transition state/intermediate of beta-lactam hydrolysis. J. Mol. Biol. 1993, 234, 165-178. [CrossRef]

30. Aldridge, W.N. Some properties of specific cholinesterase with particular reference to the mechanism of inhibition by diethyl p-nitrophenyl thiophosphate (E 605) and analogues. Biochem. J. 1950, 46, 451-460. [CrossRef] 
31. Carletti, E.; Colletier, J.-P.; Schopfer, L.M.; Santoni, G.; Masson, P.; Lockridge, O.; Nachon, F.; Weik, M. Inhibition Pathways of the Potent Organophosphate CBDP with Cholinesterases Revealed by X-ray Crystallographic Snapshots and Mass Spectrometry. Chem. Res. Toxicol. 2013, 26, 280-289. [CrossRef]

32. Sanson, B.; Nachon, F.; Colletier, J.-P.; Froment, M.-T.; Toker, L.; Greenblatt, H.M.; Sussman, J.L.; Ashani, Y.; Masson, P.; Silman, I.; et al. Crystallographic Snapshots of Nonaged and Aged Conjugates of Soman with Acetylcholinesterase, and of a Ternary Complex of the Aged Conjugate with Pralidoxime. J. Med. Chem. 2009, 52, 7593-7603. [CrossRef] [PubMed]

33. Bharathi, S.; Wong, P.T.; Desai, A.; Lykhytska, O.; Choe, V.; Kim, H.; Thomas, T.P.; Baker, J.R.; Choi, S.K. Design and mechanistic investigation of oxime-conjugated PAMAM dendrimers as the catalytic scavenger of reactive organophosphate. J. Mater. Chem. B 2014, 2, 1068-1078. [CrossRef]

34. Tassoni, R.; Blok, A.; Pannu, N.S.; Ubbink, M. New Conformations of Acylation Adducts of Inhibitors of $\beta$-Lactamase from Mycobacterium tuberculosis. Biochemistry 2019, 58, 997-1009. [CrossRef] [PubMed]

35. Toia, R.F.; Casida, J.E. Phosphorylation, "aging" and possible alkylation reactions of saligenin cyclic phosphorus esters with $\alpha$-chymotrypsin. Biochem. Pharmacol. 1979, 28, 211-216. [CrossRef]

36. Carletti, E.; Schopfer, L.M.; Colletier, J.-P.; Froment, M.-T.; Nachon, F.; Weik, M.; Lockridge, O.; Masson, P. Reaction of Cresyl Saligenin Phosphate, the Organophosphorus Agent Implicated in Aerotoxic Syndrome, with Human Cholinesterases: Mechanistic Studies Employing Kinetics, Mass Spectrometry, and X-ray Structure Analysis. Chem. Res. Toxicol. 2011, 24, 797-808. [CrossRef] [PubMed]

37. Fukuto, T.R. Mechanism of Action of Organophosphorus and Carbamate Insecticides. Environ. Health Perspect. 1990, 87, 245-254. [CrossRef] [PubMed]

38. Otwinowski, Z.; Minor, W. Processing of X-ray diffraction data collected in oscillation mode. In Methods in Enzymology; Academic Press: Cambridge, MA, USA, 1997; Vol. 276, pp. 307-326.

39. Adams, P.D.; Afonine, P.V.; Bunkoczi, G.; Chen, V.B.; Davis, I.W.; Echols, N.; Headd, J.J.; Hung, L.-W.; Kapral, G.J.; Grosse-Kunstleve, R.W.; et al. PHENIX: A comprehensive Python-based system for macromolecular structure solution. Acta Crystallogr. Sect. D 2010, 66, 213-221. [CrossRef] [PubMed]

40. Emsley, P.; Lohkamp, B.; Scott, W.G.; Cowtan, K. Features and development of Coot. Acta Crystallogr. Sect. D 2010, 66, 486-501. [CrossRef] [PubMed]

41. Pettersen, E.F.; Goddard, T.D.; Huang, C.C.; Couch, G.S.; Greenblatt, D.M.; Meng, E.C.; Ferrin, T.E. UCSF Chimera-a visualization system for exploratory research and analysis. J. Comput Chem 2004, 25, 605-1612. [CrossRef] [PubMed]

42. Zhang, Y.; Skolnick, J. TM-align: A protein structure alignment algorithm based on the TM-score. Nucleic Acids Res. 2005, 33, 2302-2309. [CrossRef]

43. Naas, T.; Oueslati, S.; Bonnin, R.A.; Dabos, M.L.; Zavala, A.; Dortet, L.; Retailleau, P.; Iorga, B.I. Beta-lactamase database (BLDB) - structure and function. J. Enzym. Inhib. Med. Chem. 2017, 32, 917-919. [CrossRef] [PubMed]

44. Berman, H.M.; Westbrook, J.; Feng, Z.; Gilliland, G.; Bhat, T.N.; Weissig, H.; Shindyalov, I.N.; Bourne, P.E. The Protein Data Bank. Nucleic Acids Res. 2000, 28, 235-242. [CrossRef] [PubMed]

45. Hall, T.A. BioEdit: A User-Friendly Biological Sequence Alignment Editor and Analysis Program for Windows 95/98/NT; Nucleic acids symposium series, 1999; Oxford University Press: Oxford, UK, 1999; pp. 95-98.

(C) 2019 by the authors. Licensee MDPI, Basel, Switzerland. This article is an open access article distributed under the terms and conditions of the Creative Commons Attribution (CC BY) license (http://creativecommons.org/licenses/by/4.0/). 